\title{
EDUCAÇÃO CTS: UMA PROPOSTA PARA A FORMAÇÃ̃O DE CIENTISTAS E ENGENHEIROS
}

\author{
Rafael de Brito Dias* \\ Milena Pavan Serafim**
}

Recebido em: 30 de agosto de 2009 Aprovado em: 30 de setembro de 2009

* Doutorando do Programa de Política Científica e Tecnológica da Universidade Estadual de Campinas. E-mail: rafaeldias@ige.unicamp.br.

**Doutoranda do Programa de Política Científica e Tecnológica da Universidade Estadual de Campinas. E-mail: milena@ige.unicamp.br.

Resumo: Nos últimos anos, vem ganhando força no Brasil a ideia do cientista/engenheiro inovador. Em um contexto onde a linha que separava empresas e universidades se torna cada vez menos perceptível, vozes de ambos esses mundos professam as vantagens atreladas a mudanças possíveis e desejáveis na formação desses profissionais. O discurso mais comum prega a necessidade de formar cientistas e engenheiros capazes de combinar profundo conhecimento técnico e científico a habilidades gerenciais, o que exigiria uma série de mudanças curriculares. Implícito nesse discurso está, obviamente, o diagnóstico de que o modelo vigente de formação desses profissionais tornouse inadequado à atual realidade brasileira. No presente artigo, expressamos nossa concordância em relação ao diagnóstico. De fato, o perfil dos cientistas e engenheiros formados atualmente no Brasil não é condizente com a realidade social brasileira. Contudo, discordamos completamente do modelo alternativo de formação que é frequentemente proposto, uma vez que, em nossa avaliação, esse modelo também provaria ser disfuncional. Encerramos este trabalho apresentando um outro modelo alternativo que pensamos ser mais adequado para o Brasil.

Palavras-chave: Educação em ciência. Tecnologia e sociedade. Ciência e tecnologia. Cientistas e engenheiros. Modelo de formação.

\section{CTS EDUCATION: A PROPOSAL FOR THE EDUCATION OF SCIENTISTS AND ENGINEERS}

Abstract: The idea of the innovating scientist/engineer has been gaining strength in the last few years. In a context where the line that separated industries and universities is becoming increasingly elusive, voices from both sides profess the advantages related to possible and desirable changes in the education of these professionals. The common discourse emphasizes the need to produce scientists and engineers capable of combining profound technical knowledge and managerial skills, which would demand a series of curricular changes. Obviously, the diagnosis that the current education model for these professionals has become inadequate to respond to Brazilian reality is implicit in this discourse. In this paper, we express our agreement concerning this diagnosis: the profile of scientists and engineers currently graduating in Brazil is not coherent with Brazilian social reality. However, we completely disagree on the alternative model of education which is frequently proposed, since in our evaluation this model would also prove to be dysfunctional. We conclude this paper by presenting another alternative model, which we consider more adequate to Brazil.

Key words: Science and technology. Scientists and engineers. Educational model. Education in science. Technology and society. 


\section{Introdução}

A concepção acerca das relações entre ciência, tecnologia e sociedade (CTS) no Brasil (e, de fato, no conjunto da América Latina) sempre apresentou uma orientação fortemente associada à chamada visão ofertista linear em ciência e tecnologia (C\&T). Essa visão, que se tornou particularmente forte a partir dos anos cinquenta, pode ser sintetizada pela ideia do "quanto mais, melhor". São frequentes os discursos que se baseiam na ideia de "quanto mais ciência e tecnologia, melhor", por exemplo.

Com efeito, não raramente um fazedor de políticas da área de C\&T reforça a visão ofertista linear, apresentando uma solução única e definitiva para uma série de problemas estruturais, decorrentes da exploração colonial e, posteriormente, da inserção do Brasil na periferia do capitalismo. Assim, um incremento no volume dos recursos financeiros destinados à pesquisa científica e tecnológica, ou um aumento no número de cientistas e engenheiros $(\mathrm{C} \& \mathrm{E})$ formados são usualmente tidos como panaceias.

Nos últimos vinte anos, parece ter ocorrido uma mudança importante na visão ofertista linear acerca das relações CTS. Mais especificamente, parece ter sido conformada uma aliança entre essa visão e um enfoque teórico analíticodescritivo oriundo da Economia, que aqui chamaremos grosseiramente de enfoque Evolucionário (ou Evolucionista).

Algumas das preocupações principais do enfoque Evolucionário remetem a questões como o caráter evolutivo do sistema capitalista (uma analogia ao darwinismo), a importância da empresa como elemento central da economia e, sobretudo, ao papel das inovações tecnológicas como principais indutoras do progresso econômico das sociedades contemporâneas (DIAS, 2005). Esses elementos do enfoque Evolucionário fundiram-se à visão ofertista linear, conformando o substrato cognitivo dos fazedores de políticas (policy makers) de C\&T no Brasil e, aparentemente, da própria comunidade de pesquisa.

A aliança ofertismo-evolucionismo passou, portanto, a permear as discussões acerca dos problemas científicos e tecnológicos brasileiros a partir de meados dos anos oitenta. Essas reflexões estão presentes em diferentes níveis (acadêmico, político, empresarial) e, curiosamente, são compartilhadas tanto pela esquerda quanto pela direita (DAGNINO, 2004a). Um reflexo da conformação dessa aliança pode ser verificado na emergência de vozes que pregam mudanças na forma de pensar de cientistas e engenheiros, condicionada por uma mudança na formação desses profissionais.

Um dos espaços no qual o discurso da aliança ofertismo-evolucionismo mais avançou nos últimos anos remete a um terreno nebuloso, situado entre a 
academia e a empresa. Inspiradas por experiências bem-sucedidas nos EUA, na Europa e na Ásia, muitas iniciativas no Brasil vêm tentando aproximar esses dois mundos, aparentemente tão distintos. Dessa preocupação decorrem uma série de políticas e de arranjos institucionais (parques e pólos tecnológicos, incubadoras de empresas) que, emulados de forma acrítica, são transportados para uma realidade completamente distinta daquela para a qual foram concebidos. (DAGNINO; THOMAS, 2001)

Evidentemente, não se pode pensar nessas transformações verificadas na concepção acerca das relações CTS sem que se leve em consideração as mudanças contextuais mais amplas verificadas a partir dos anos oitenta, como a globalização e a ascensão da ideologia política neoliberal. Isso se torna mais evidente se entendermos esses dois processos como elementos inseridos em uma lógica de "privatização do público", que se manifesta, inclusive, no plano das idéias. Ao menos parcialmente, essa ideia parece explicar, por exemplo, o por quê de algumas universidades públicas brasileiras estarem tão comprometidas em incorporar ao currículo das engenharias disciplinas da área de gestão. E, quase que simultaneamente, essa ideia parece explicar a escassez de disciplinas voltadas à formação de profissionais efetivamente comprometidos com questões sociais, ou de interesse público, nas próprias universidades públicas brasileiras.

Nos próximos itens que compõem este trabalho, fazemos algumas considerações a respeito da visão convencional ao redor das relações CTS, levantando alguns questionamentos a respeito dela. Conferimos particular ênfase na crítica à visão do "cientista e engenheiro inovador", ilustrando nossa argumentação com algumas reflexões acerca do caso da Universidade Estadual de Campinas (UNICAMP). Em seguida, analisamos um modo de conceber as relações CTS que julgamos ser mais adequado para entender toda a complexidade que as cerca. Por fim, apresentamos um modelo de educação que, acreditamos, poderia incorporar essa visão crítica.

\section{Criticando a visão convencional acerca das relações CTS}

Para refletir de forma crítica acerca das relações comumente estabelecidas acerca das relações CTS, convém utilizar alguns exemplos concretos e traçar um paralelo entre a realidade brasileira com a realidade norte-americana, entendida por muitos como um modelo a ser emulado e perseguido.

No Brasil, as empresas são responsáveis por apenas 38,2\% do total dos recursos destinados às atividades de $\mathrm{P} \& \mathrm{D}$. As empresas norte-americanas, por sua vez, são responsáveis por $63,1 \%$ do total desses recursos. (UNESCO, 2004) 
No que se refere ao pessoal alocado em atividades de $\mathrm{P} \& \mathrm{D}$, os dados também são enfáticos: apenas $11 \%$ do total dos cientistas e engenheiros no Brasil estão empregados em empresas, contra 79\% nos EUA (BRITO CRUZ, 2004). No Brasil, o complexo industrial emprega diretamente cerca de 9 mil pesquisadores envolvidos em atividades de P\&D (BRITO CRUZ, 2004). Nos EUA, esse número é superior a um milhão. (MORIS, 2004)

Observando esse quadro, os defensores da visão ofertista linear percebem a vasta distância que separa o País dos EUA, no que diz respeito às atividades de ciência e tecnologia nas empresas. Ao refletir sobre essa condição, parecem ignorar os elementos estruturais historicamente determinados que impõem essas diferenças. Tratam a questão interpretando de forma superficial as relações entre as variáveis, desprezando fatores cruciais para a análise.

Assim, fatores essenciais para a compreensão da situação brasileira, ligados ao âmbito da ciência e da tecnologia (como, por exemplo, a dependência tecnológica) são analisados de maneira descolada do contexto histórico mais amplo. Analiticamente, não parece ser interessante pensar a questão da dependência tecnológica sem levar em consideração as vicissitudes associadas à exploração colonial e à inserção periférica da economia brasileira. Entretanto, isso parece ocorrer com muita freqüência.

Os dilemas relacionados à debilidade científica e tecnológica apresentada pelo Brasil passam, como conseqüência das limitações dessa natureza, a ser enfrentados com respostas excessivamente superficiais, apoiadas em experiências concebidas para solucionar os problemas existentes em realidades completamente distintas da brasileira. São experiências emuladas de maneira acrítica a partir dos países centrais. Por não darem conta de toda a complexidade e das particularidades da realidade brasileira, constituem medidas inócuas.

O raciocínio percorrido pelos defensores da visão ofertista linear parece ser extremamente simples, considerando as soluções que propõem, sob a forma de políticas: "se as empresas brasileiras investem pouco em $\mathrm{P} \& \mathrm{D}$, devemos criar mecanismos que incentivem um volume maior de investimentos por parte delas (por exemplo, os fundos setoriais)" ou "se as empresas empregam poucos profissionais em atividades de $\mathrm{P} \& \mathrm{D}$, devemos formar mais cientistas e engenheiros". Essa ideia tem sido amplamente difundida tanto no meio acadêmico quanto no empresarial.

Implícito na ideia de que é necessário que ocorra uma adequação, ou uma reorientação "para o mercado” do currículo de engenharias no Brasil, está a percepção, ao nosso ver equivocada, de que a empresa privada nacional deman- 
daria um profissional que combinasse conhecimentos técnicos e habilidades gerenciais.

Contudo, se o aumento da oferta de mestres e doutores teve um impacto importante sobre a produção científica nacional, efeitos semelhantes não foram verificados no setor produtivo. A despeito da relativa escassez de pós-graduados no Brasil (em comparação aos EUA), há que se ressaltar que, em relação à demanda do setor produtivo, existe um excesso de profissionais com esse nível de qualificação no País. Conforme destaca a Pesquisa Industrial de Inovação Tecnológica (IBGE, 2000), o Brasil possui aproximadamente 3.000 mestres e doutores engajados em atividades de pesquisa e desenvolvimento (P\&D) em empresas, um número muito baixo em relação ao fluxo de pós-graduados formados anualmente. Esse número equivale, segundo a Pesquisa, a 7,1\% do total de profissionais ocupados em atividades de $\mathrm{P} \& \mathrm{D}$.

O sistema produtivo brasileiro, em virtude de seu caráter periférico, não demanda um número elevado de pesquisadores para desenvolverem atividades de $\mathrm{P} \& \mathrm{D}$, de modo que o excesso de recursos humanos qualificados formados anualmente no País não é absorvido por esse setor. As empresas multinacionais preferem conduzir suas atividades de $\mathrm{P} \& \mathrm{D}$ em seus laboratórios instalados nos países centrais.

Como consequência desse quadro, grande parte do contingente excessivo de profissionais busca oportunidades dentro do complexo superior de ensino e pesquisa, ou alternativas de trabalho no exterior - o fenômeno da "fuga de cérebros", destacado por Leite Lopes (1978) - ou, ainda, passa a desempenhar atividades de caráter estritamente administrativo dentro de empresas privadas. A despeito dessa situação, de natureza estrutural, o aumento da oferta de profissionais qualificados é visto como uma prioridade por parte do governo, o que constitui um claro reflexo da mentalidade ofertista linear.

Evidentemente, o que se questiona não é a importância da formação de profissionais qualificados, mas a confiança injustificada nessas medidas, consideradas como sendo suficientes para alavancar o desenvolvimento científico e tecnológico e, através disso, promover o desenvolvimento econômico e social. Além disso, o próprio modelo de formação desses profissionais é passível de críticas. O currículo dos cursos de graduação das áreas de ciências e engenharias, por exemplo, não incorpora elementos que poderiam contribuir com a formação de profissionais aptos a atuar sobre os problemas colocados no contexto dos países periféricos, sendo apenas um reflexo daqueles dos países centrais. Essa questão será tratada com maior profundidade no próximo item. 


\section{Cientistas e engenheiros inovadores - alguns equívocos}

Grande parte dos equívocos associados à dinâmica assumida pelas relações CTS em países periféricos, como é o caso do Brasil, decorre de interpretações equivocadas acerca da realidade local, bem como da maneira superficial com que são tratados alguns fenômenos sociais.

Um exemplo disso pode ser encontrado na forma com que um elemento central das sociedades capitalistas - a empresa - ou, mais especificamente, suas atribuições, são entendidas. A forma com que empresários, acadêmicos e fazedores de políticas vêem esse agente econômico no Brasil é apenas um reflexo daquilo que a empresa representa nos países centrais, onde, de fato, constitui uma figura mais próxima de sua imagem clássica idealizada.

Uma outra questão essencial dentro dessa discussão remete às reflexões acerca da neutralidade e do determinismo da ciência e da tecnologia. O conhecimento produzido na América Latina mostra-se pouco útil como forma de responder aos problemas colocados na região. Essa afirmação pode, a princípio, parecer espantosa, mas uma análise razoavelmente aprofundada da realidade latino-americana de fato aponta para essa constatação.

O "senso comum" aceita a ideia de que conhecimento, em especial o científico e o tecnológico, constitui um elemento fundamental dentro de qualquer estratégia de desenvolvimento econômico e social bem-sucedida e, de fato, o é. Mas, como argumentaremos a seguir, essa ideia contém alguns equívocos, e deve ser tratada com cautela.

A forma com que o "senso comum" entende a maneira pela qual o conhecimento é gerado e a sua relação com a sociedade acaba por criar uma imagem mitificada da ciência e da tecnologia distorcendo, inclusive, o papel dessas dentro das diversas estratégias de desenvolvimento social e econômico, atualmente adotadas ou defendidas como alternativas interessantes.

Dessa maneira, ciência e tecnologia são comumente entendidas de duas formas antagônicas: por uns, como uma panaceia, a solução para todos os problemas da sociedade (aqui se encaixam, por exemplo, os defensores da economia da inovação); por outros, como um câncer, que deve ser extirpado a fim de libertar a sociedade de todos os males que a cercam (postura que pode ser associada aos movimentos tecnófobos).

Essas duas posições, ao exaltar ou rechaçar por completo a produção de conhecimento científico e tecnológico, acabam ignorando um ponto crucial no entendimento da própria natureza desse conhecimento e da forma como este se relaciona com a sociedade: o fato de existirem valores sociais "embutidos" no conhecimento científico e tecnológico. 
Esses valores, presentes no ambiente social que permeia o ambiente no qual o conhecimento é gerado (em universidades, institutos de pesquisa, empresas, etc.) são incorporados à ciência e à tecnologia, ou seja, são passados pelos atores sociais (pesquisadores, engenheiros, etc.) ao conhecimento que estes produzem.

Reconhecer a idéia de que o conhecimento científico e tecnológico de fato contém valores sociais implica a rejeição da idéia de que esse conhecimento é neutro, ou seja, independente do ambiente social no qual é gerado. Além disso, desmistifica, em alguma medida, a imagem que tem o "senso comum" do processo de produção de conhecimento, entendido como algo quase que etéreo ou sobrenatural.

\section{A Unicamp: um exemplo do foco nos cientistas e engenheiros inovadores}

Recentemente, algumas universidades públicas brasileiras (notadamente as estaduais paulistas - Universidade de São Paulo, Universidade Estadual de Campinas e Universidade Estadual Paulista Júlio de Mesquita Filho) têm direcionado seus esforços no sentido de fomentar a inovação. Para compreender essa transformação, é preciso contemplar a trajetória histórica mais ampla seguida pela relação pesquisa-produção (ou universidade-empresa, como é mais comumente chamada).

Durante as últimas cinco décadas, a relação pesquisa-produção foi marcada por, basicamente, dois momentos fundamentais, a saber, o vinculacionismo e o neovinculacionismo.

O vinculacionismo é definido por Oliveira (2003, p. 22) como uma "tentativa de gerar laços entre a comunidade de pesquisa, por meio das instituições de pesquisa e desenvolvimento ( $\mathrm{P} \& \mathrm{D})$ e o setor produtivo, com a pretensão de garantir que o resultado dos desenvolvimentos de C\&T chegue à sociedade, aos seus potenciais usuários" (p. 22). Seria, assim, uma tentativa forçada (ou ofertista) de criar e estreitar laços entre a comunidade de pesquisa e o setor produtivo. (DAGNINO; THOMAS; GARCIA, 1997)

A partir da década de 1980, contudo, observou-se uma mudança nessa postura. Gradualmente, a universidade passa a ocupar o espaço central dentro da relação pesquisa-produção, deslocando as funções que anteriormente eram cumpridas pelos institutos de $\mathrm{P} \& \mathrm{D}$ e pelo setor produtivo. A essa nova forma de relação Dagnino, Thomas e Garcia (1997) chamaram de neovinculacionismo.

Com relação a essa nova forma assumida pela relação pesquisa-produção, Oliveira (2003, p. 33) coloca que: 
Dessa forma, foram criados mecanismos como os pólos e parques tecnológicos, as incubadoras de empresas e os escritórios de transferência de tecnologia e registro de patentes. Em muitos casos, a iniciativa quanto ao financiamento inicial desses empreendimentos fica a cargo da instituição de ensino. Diante disso, a universidade deveria deixar de atuar como provedor gratuito de conhecimento para passar a ser um ator do processo de privatização do conhecimento, através da cobrança de direitos pelos resultados das pesquisas por ela realizada ou apoiada.

Essa trajetória da relação pesquisa-produção revela uma transformação importante sofrida pela universidade pública brasileira ao longo das últimas décadas. Reflete, ademais, uma tendência mais ampla, a de privatização branca sofrida por quase todas as instituições de natureza pública. No caso particular da universidade, esse processo tem se dado através do rapto da agenda de pesquisa (pública) por temas de interesse estritamente privado.

Contudo, mais recentemente (a partir de meados da década de 1990), observa-se a adoção de uma postura cada vez mais agressiva, por parte da universidade, na busca pela inovação. Naturalmente, a causa central dessa mudança foi a procura por novas alternativas de financiamento para a pesquisa universitária.

Como conseqüência desse processo, nota-se uma situação na qual a universidade pública, através da comunidade de pesquisa, passa a defender uma agenda conformada por interesses que são característicos de empresas. Com isso, passa por uma transmutação que desvirtua seus próprios compromissos para com a sociedade que a mantém.

O discurso adotado pelas universidades públicas brasileiras, advogando a importância da inovação para o desenvolvimento econômico, da disseminação de uma cultura inovadora e da criação de laços entre universidades e empresas, tem sido bem recebido pela sociedade. Mas esse discurso, mais do que o reflexo vazio de uma realidade inexistente, representa uma engenhosa, ainda que inconsciente, estratégia de marketing institucional por parte de algumas das universidades públicas brasileiras.

A Universidade Estadual de Campinas (Unicamp) constitui o caso emblemático dessa transformação. Ao longo dos últimos anos, a instituição tem se preocupado em enfatizar sua preocupação com a questão da inovação. A tabela abaixo ilustra essa constatação: 
Tabela 1 - Pedidos de depósito de patentes solicitados pela Unicamp (1989 - 2007)

\begin{tabular}{cc}
\hline Período & Número de pedidos \\
\hline $1989-1996$ & 67 \\
$1997-2001$ & 128 \\
$2002-2007$ & 337 \\
\hline
\end{tabular}

Fonte: elaboração dos autores a partir dos dados da Agência de Inovação da Unicamp. Disponível em: < http:// www.inova.unicamp.br>. Acesso em:.

Os dados acima apontam para três períodos da trajetória da Unicamp no que diz respeito à inovação, aqui medida através do número de pedidos de depósito de patentes solicitados pela instituição. No primeiro período (1989 a 1996), o número de solicitações foi relativamente baixo, tendo ficado, em média, abaixo de oito pedidos por ano. A partir de 1997, há uma inflexão nesse comportamento. A universidade passa a realizar de forma mais agressiva suas atividades de apoio à inovação. Conseqüentemente, eleva o número de pedidos para uma média próxima a 25 por ano. O terceiro período, que se inicia em 2002. é marcado pela explosão do número de pedidos de depósito de patentes solicitados pela Unicamp. A média anual de solicitações nesse período foi de cerca de 56. Esse comportamento foi fortemente influenciado pelos esforços da Agência de Inovação da universidade (Inova), criada em 2003, e que representou a consolidação da preocupação da Universidade com a inovação.

De acordo com o sítio da Inova (2009) na Internet, sua missão é:

fortalecer as parcerias da Unicamp com empresas, órgãos de governo e demais organizações da sociedade, criando oportunidades para que as atividades de ensino e pesquisa se beneficiem dessas interações e contribuindo para o desenvolvimento econômico e social do País ${ }^{1}$.

Sua atuação, entretanto, denuncia uma preocupação maior com a aproximação da universidade em relação ao setor produtivo.

Em uma reportagem publicada pelo Jornal da Unicamp em 27 de setembro de 2007 fica evidente a preocupação da Universidade, assim como de outras instituições, para com a questão da inovação e da aproximação em relação ao setor produtivo. O argumento é o de que é preciso aumentar os investimentos empresariais nas universidades brasileiras para que estes atinjam patamares semelhantes ao dos países centrais.

1 Fonte: Disponível em: <http://www.inova.unicamp.br/site/06/paginas/visualiza_conteudo. php? conteudo=1>. Acesso em: jan. 2009. 
Contudo, mesmo nesses países - nos quais, vale lembrar, a articulação entre o complexo de ensino superior e de pesquisa e o setor produtivo é muito mais fluida e natural do que aquela que se observa no Brasil - esses investimentos representam uma parcela pequena do orçamento universitário (cerca de $5 \%$ nos EUA e de 6,5\% na Europa). A despeito disso, e de forma não desinteressada, a comunidade de pesquisa brasileira segue defendendo a realização de esforços direcionados à inovação por parte das universidades públicas.

Na mesma direção desse argumento, vale ressaltar que a comunidade de pesquisa brasileira frequentemente aponta o volume dos gastos em P\&D a cargo das universidades como um indicador de que seu potencial "empreendedor" é subaproveitado. No Brasil, a universidade é responsável por 1,6\% desses gastos; o governo, por 60,2\%; e as empresas, por $38,2 \%$. Mas esse argumento parece ignorar o fato de que, mesmo nos países centrais, a universidade participa pouco nessa função. Nos EUA, por exemplo, as universidades são responsáveis por $5,7 \%$ desses gastos; o governo, por $31,2 \%$; e as empresas, por $63,1 \%$.

Esses aspectos constituem exemplos de práticas orientadas à formação de cientistas e engenheiros inovadores. O que se nota é que, de forma quase que inconsciente e aparentemente desarticulada, universidades como a Unicamp têm, por meio dessas ações, cumprido com muita propriedade um papel fundamental na consolidação do modelo neoliberal.

\section{Cientistas e engenheiros verdadeiramente inovadores}

Nossa argumentação até este ponto esteve apoiada em uma reflexão bastante simples. O modelo já existente de formação de cientistas e engenheiros é disfuncional em relação à realidade brasileira, tanto quanto o modelo alternativo proposto, o do "cientista/engenheiro inovador".

A razão dessa não-funcionalidade é a mesma: em ambos os casos, o modelo de formação não é pensado de forma integrada ao contexto mais amplo da sociedade brasileira. No caso do modelo vigente, isso não é feito porque este foi concebido dentro de uma racionalidade positivista extrema: o bom cientista/ engenheiro é aquele que domina a ciência e a técnica. O modelo alternativo proposto, por sua vez, não o faz porque foi concebido a partir de uma percepção equivocada da realidade brasileira.

Além disso, esse modelo alternativo, assim como o vigente, está excessivamente orientado para a demanda. Como a riqueza e a renda no Brasil são altamente concentradas, a demanda é muito restrita. A necessidade, que por sua vez, pode ser entendida de forma estilizada como sendo inversamente 
proporcional à riqueza e à renda, é algo muito presente na realidade brasileira. A pesquisa científica e tecnológica brasileira, para buscar uma maior proximidade com a realidade social, assumindo um caráter mais relevante, deveria ser orientada não pela demanda que erroneamente se imagina existir, mas pelas necessidades concretas da sociedade.

Como deveria ser, portanto, o cientista/engenheiro verdadeiramente inovador no Brasil? Para responder a essa pergunta, basta reconhecer quais são as necessidades sociais mais urgentes.

$\mathrm{O}$ cientista/engenheiro verdadeiramente inovador no Brasil seria aquele capaz de colaborar, através de suas atividades de pesquisa, com a solução de problemas como o déficit de saneamento e o déficit habitacional, por exemplo. Não poderiam esses problemas, que atingem milhões de brasileiros, ser atenuados através da ciência e da tecnologia?

De fato, o conhecimento científico e tecnológico poderia (e, de fato, deveria) ser utilizado como forma de atacar esses problemas. Contudo, o conhecimento existente parece não ser o mais adequado para tanto. Para alcançar as mudanças desejadas, é preciso reconstruir o conhecimento científico e tecnológico.

Caso efetivamente desejemos criar uma sociedade mais justa e democrática, precisaremos de tecnologias distintas das convencionais, capazes de dar suporte a um estilo alternativo de sociedade.

De um modo geral, a tecnologia convencional pode ser definida a partir de um conjunto de características (relativas a seus efeitos sobre o trabalho, à sua escala de produção ótima, aos seus efeitos sobre o meio-ambiente, às características dos insumos utilizados na produção, ao ritmo da produção, ao tipo de controle exercido sobre os trabalhadores, etc.) que a distingue de tipos alternativos de tecnologias, como é o caso da Tecnologia Social (TS). (DAGNINO, 2004b)

Conforme aponta Dagnino (2004b), a tecnologia convencional é inerentemente poupadora de mão-de-obra, o que pode ser verificado na constante substituição do trabalho humano por trabalho mecânico. A tecnologia convencional é segmentada, não permitindo que o produtor direto exerça controle sobre a produção; é alienante, pois suprime a criatividade do produtor direto; é hierarquizada, pois exige que haja a posse privada dos meios de produção e o controle sobre o trabalho; tem como objetivo principal (senão único) maximizar a produtividade, ainda que isso tenha efeitos negativos sobre o nível de emprego; a tecnologia convencional é, ainda, irradiada pelas empresas dos países centrais e simplesmente absorvida de forma acrítica pelas empresas dos países periféricos; por fim, a tecnologia convencional impõe aos países periféricos 
padrões que são orientados pelos mercados dos países centrais, de alta renda, e não pelos mercados locais, de renda altamente concentrada.

Assim, frente às considerações apresentadas acima, é plausível afirmar que a tecnologia convencional reforça a dualidade capitalista, submetendo trabalhadores a detentores dos meios de produção e países periféricos a países centrais, perpetuando e ampliando as assimetrias de poder dentro das relações sociais e políticas.

A tecnologia social, por sua vez, pode ser entendida como antítese do que representa a tecnologia convencional. Essa forma alternativa de tecnologia privilegiaria soluções simples, baratas e de fácil reaplicação como forma de sanar os problemas sociais colocados nos países periféricos a partir de uma perspectiva local. Mais que um conceito definido e focado no "produto" (o artefato tecnológico), a tecnologia social se destaca por seu caráter de valorização de construção processual.

Segundo Dagnino (2004b), a tecnologia social deveria ter como base os empreendimentos autogestionários e as micro e pequenas empresas. Assim, a TS deveria ser adaptada à pequena escala, tanto no sentido físico quanto financeiro, o que favoreceria os trabalhadores e pequenos proprietários em geral, além de não criar uma discriminação entre patrões e empregados e permitir a plena utilização do potencial criativo do produtor direto. Por fim, a tecnologia social estaria mais imbricada à realidade das sociedades locais, de modo que pudesse gerar respostas mais adequadas aos problemas colocados em um determinado contexto. No caso do Brasil, por exemplo, isso se traduziria em um deslocamento do foco de destino da produção, do mercado externo, de alta renda, para o mercado interno, de massa.

Dessa forma, observa-se que, enquanto a tecnologia convencional é funcional para a grande empresa privada (em especial para as grande empresas multinacionais), a tecnologia social favoreceria, principalmente, os trabalhadores e os pequenos proprietários. (DAGNINO, 2004b)

\section{Educação em ciência, tecnologia e sociedade}

O modelo de formação focado no mercado e sustentado pela figura do engenheiro inovador é colocado como uma alternativa ao formato tradicional dos cursos de engenharia, por autores como Silveira (2005). Essa não é, contudo, a única alternativa proposta. Existem outras, como, por exemplo, aquela que defende uma "humanização" do ensino de ciências e engenharias, e a proposta do movimento de Educação em Ciência, Tecnologia e Sociedade (ou Educação 
CTS). Consideramos que essa última, em particular, poderia ser um modelo interessante a ser adotado no ensino médio e superior brasileiro, a exemplo do que já vem ocorrendo em países como Espanha e México. Convém, neste momento, apresentar brevemente esse movimento, ainda pouco difundido no Brasil.

A Educação CTS representa uma das diversas frentes de um campo acadêmico maior, o campo CTS, que apresenta um referencial bastante distinto daquele oferecido pela forma tradicional de análise das relações entre ciência, tecnologia e sociedade. O campo CTS surge, em meados da década de 1970, em um contexto de profundas mudanças na forma com que essas relações eram percebidas por acadêmicos e pela sociedade em geral.

Por um lado, as contribuições de autores associados à sociologia do conhecimento (como David Bloor e Bruno Latour) e, mais tarde, de autores associados à sociologia da tecnologia (como Trevor Pinch e Wiebe Bijker), fortaleceram, dentro da esfera acadêmica, a ideia de que era fundamental entender a total complexidade dos fenômenos científicos e tecnológicos. Para tanto, seria necessário analisar a ciência e a tecnologia como objetos não puramente técnicos, mas como resultados de processos sociais. Dessa forma, essa tradição, que se tornou conhecida como Science and Technology Studies, de origem européia, tem se preocupado com a compreensão dos antecedentes, ou condicionantes sociais da tecnologia. (LOPEZ CEREZO, 2004)

Por outro lado, os movimentos de contestação social nos EUA, como, por exemplo, os protestos contra a Guerra do Vietnã e contra a disseminação da energia nuclear e o surgimento do movimento de defesa dos direitos do consumidor, fizeram com que a tradição CTS norte-americana, ou Science, Technology and Society, nascesse com uma maior preocupação em relação às consequências, ou aos impactos sociais da ciência e da tecnologia, orientação que mantém até hoje. (LOPEZ CEREZO, 2004)

De acordo com Cutcliffe (2003), a emergência desse campo pode ser entendida como a resolução da tensão entre dois movimentos: a Ilustração, ideia moderna segundo a qual ciência e tecnologia constituem instrumentos fundamentais para a promoção de transformações sociais; e o Romantismo, que surge como uma resposta crítica à visão essencialista e triunfalista da tecnociência, expressa pela Ilustração.

Sobretudo nas duas décadas após o término da $2^{\text {a }}$ Guerra Mundial, prevaleceu a ideia da Ilustração. Predominava o consenso de que ciência e tecnologia constituíam forças inerentemente boas que necessariamente trariam progresso e desenvolvimento econômico e social. 
As ideias levantadas pelo campo CTS foram particularmente bem recebidas nos EUA e na Europa, em especial no Reino Unido, na Dinamarca, na Suécia e na Holanda. Aos poucos, essa mudança de consciência foi se consolidando, dando origem a programas (como o Programa das Dimensões Sociais da Engenharia, da Ciência e da Tecnologia, Fundação Nacional da Ciência dos EUA), instituições (como a Comissão de Regulação Nuclear norte-americana) e agremiações de cientistas e engenheiros (como a União dos Cientistas Comprometidos, também nos EUA). O fortalecimento dessa percepção crítica da ciência e da tecnologia pôde, ainda, ser verificada através do surgimento de uma série de periódicos especializados, como a Issues in Science and Technology e a Technology and Society Magazine. No ambiente acadêmico, paralelamente ao desenvolvimento do campo CTS, verificou-se um notável avanço teórico e metodológico em disciplinas como a Sociologia, a Filosofia e a História da Ciência e da Tecnologia. (CUTCLIFFE, 2003)

Ao longo dos anos oitenta e noventa, verificou-se um aumento dos cursos e programas CTS, sobretudo nos EUA e na Europa, mas também em alguns países latino-americanos, em especial no México e na Argentina.

Feita essa breve apresentação do campo CTS, convém agora apresentar os principais aspectos da Educação CTS.

Segundo Auler e Delizoicov (2006), uma das principais características da Educação CTS seria a busca pela participação e pela democratização das decisões em temas sociais envolvendo ciência e tecnologia. Assim, de acordo com os autores, haveria, nesse aspecto, uma grande possibilidade de diálogo entre a Educação CTS e o pensamento de Paulo Freire. Nas palavras desses autores, "torna-se, cada vez mais, fundamental uma compreensão crítica sobre as interações entre CTS, considerando que a dinâmica social contemporânea está fortemente marcada pela presença da CT". (p. 338)

Um aspecto relacionado à Educação CTS que merece ser destacado está ligado à ideia de multidisciplinariedade. Dentro dessa concepção, ciência e tecnologia são abordadas a partir de diversos campos disciplinares (como sociologia, história, economia, filosofia, ciência política, etc.) e de forma integrada.

Cutcliffe (2003) afirma que, com alguma flexibilidade conceitual, a Educação CTS poderia ser caracterizada como interdisciplinar, embora esse traço seja ainda muito incipiente. De qualquer forma, o autor aponta para uma tendência gradual, iniciada no final da década de 1980, de fortalecimento dessa característica de interdisciplinariedade da Educação CTS.

Talvez o aspecto mais interessante a respeito da Educação CTS seja aquele referente à questão metodológica. Nas palavras de López Cerezo (2004, p. 
28) "Não se pode pretender uma renovação crítica do ensino restringindo tal mudança somente aos conteúdos". Nesse sentido, a Educação em CTS propõe que ocorra uma mudança significativa na própria maneira de ensinar. Auler et al. (2005) relatam uma experiência bastante interessante neste sentido.

As contribuições da sociologia da ciência e da tecnologia, relativas à interpretação desses elementos como sendo resultantes de processos sociais e não, portanto, como soluções cognitivas e técnicas ótimas, representam um passo fundamental em direção a uma visão crítica e completa acerca das relações CTS. Segundo Von Linsingen (2006), isso justificaria uma mudança na forma de ensinar disciplinas das áreas de ciências e engenharias, que deveria incorporar às tradicionais preocupações disciplinares (dentre as quais a eficiência é a mais paradigmática) um conjunto de variáveis distintas, como, por exemplo, a importância de problemas locais ou questões cotidianas.

\section{Considerações finais}

Neste trabalho apresentamos uma discussão, que nos parece fundamental, acerca da desconexão entre o modelo de formação de cientistas e engenheiros no Brasil e a realidade social verificada no País. Esse diagnóstico é também um ponto de partida para outras análises, que resultam em diferentes recomendações de modelos alternativos. Uma delas em particular - aquela que prega a formação de cientistas e engenheiros com base em um modelo de gestão e voltado para as empresas privadas - parece estar gradualmente se tornando a alternativa mais amplamente defendida.

Procuramos aqui fazer uma reflexão a respeito dessa proposta, associando-a ao projeto neoliberal e questionando a sua pertinência ao contexto brasileiro. Por fim, apresentamos uma outra alternativa, a da Educação CTS, que nos parece ser mais adequada à realidade nacional e que poderia, acreditamos, vir a compor um projeto maior de construção de uma sociedade distinta, apoiada em um estilo diferente de educação e de construção do conhecimento.

\section{Referências}

AULER, Décio et al. Transporte particular x coletivo: intervenção curricular pautada por interações entre ciência-tecnologia-sociedade. Enseñanza de lãs Ciencias, Barcelona, v. extra, número especial, p. 01-06, 2005. 
AULER, Décio; DELIZOICOV, Demétrio. Ciência-tecnologia-sociedade: relações estabelecidas por professores de ciências. Revista Electrónica de Enseñanza de lãs Ciencias, Espanha, v. 5, n. 2, p. 337-355, 2006.

BRITO CRUZ, Carlos Henrique. A universidade, a empresa e a pesquisa que o país precisa. In: SANTOS, Lucy et al. Ciência, tecnologia e sociedade: 0 desafio da interação. Londrina: IAPAR, 2004.

CUTCLIFFE, Stephan. Ideas, máquinas y valores: los estudios de ciencia, tecnología y sociedad. México, D.F.: Anthropos Editorial, 2003.

DAGNINO, Renato Peixoto; THOMAS, Hernán; GARCIA, Amílcar Davyt. Vinculacionismo/ neovinculacionismo: racionalidades de la interacción Universidad-Empresa en América Latina (1955-1995). Espacios Revista Venezolana de Gestión Tecnológica, Caracas, Venezuela, v. 18, n. 1, 1997.

DAGNINO, Renato; THOMAS, H. Planejamento e políticas públicas de inovação: em direção a um marco de referência latino-americano. Planejamento e Políticas Públicas, n. 23, Brasília: IPEA, 2001.

DAGNINO, Renato. Uma política científica de esquerda num governo de esquerda? Associação Brasileira de Ciência Política. Disponível em: <www. cienciapolitica.org.br/MR6-Renato\%20Dagnino.pdf>. 2004a.

DAGNINO, Renato. A tecnologia social e seus desafios. In: Tecnologia social: uma estratégia para o desenvolvimento. Rio de Janeiro: Fundação Banco do Brasil, 2004b.

DIAS, Rafael. A política científica e tecnológica latino-americana: relações entre enfoques teóricos e projetos políticos. 2005. Dissertação (Mestrado em Política Científica e Tecnológica) - Instituto de Geociências, Universidade Estadual de Campinas, Campinas, 2005.

IBGE - INSTITUTO BRASILEIRO DE GEOGRAFIA E ESTATÍSTICA. Pesquisa industrial de inovação tecnológica. Brasília: IBGE, 2000.

INOVA. Agência de Inovação Inova UNICAMP. Disponível em: $<$ http://www.inova.unicamp.br/site/06/paginas/visualiza_conteudo. php? conteudo=1>. Acesso em: jan. 2009.

JORNAL DA UNICAMP. Contratos entre empresas e universidades são 
tímidos. Publicado em 26 de setembro de 2007. Disponível em: <http:// www.unicamp.br/unicamp/divulgacao/BDND/ND_1204/ND_1204.html>. Acesso em: jan. 2009.

LEITE LOPES, José. Ciência e libertação. Rio de Janeiro: Paz e Terra, 1978.

LOPEZ CEREZO, José Antônio. Ciência, Tecnologia e sociedade: o estado da arte na Europa e nos Estados Unidos. In: SANTOS, Lucy et al. Ciência, tecnologia e sociedade: o desafio da interação. Londrina: IAPAR, 2004.

MORIS, Francisco. Industrial R\&D Employment in the United States and in US Multinational Corporations. Science Resources Statistics, NATIONAL SCIENCE FOUNDATION, dez. 2004. Disponível em: <www.nsf.gov/ statistics/infbrief/nsf05302/nsf05302.pdf>. Acesso em: jan. 2009.

OCDE. Main Science and Technology Indicators. OCDE, nov. 2005.

OLIVEIRA, Luis José. Incubadoras universitárias de empresas e de cooperativas: contrastes e desafios. 2003. Dissertação (Mestrado em Política Científica e Tecnológica) - Instituto de Geociências, Universidade Estadual de Campinas, Campinas: DPCT/IG/UNICAMP, 2003.

SAREWITZ, Daniel. Frontiers of illusion: science, technology and politics of progress. Filadélfia: Temple University Press, 1996.

SILVEIRA, Marcos Azevedo. A formação do engenheiro inovador. Rio de Janeiro, PUC- Rio, 2005.

UNESCO. UNESCO country profiles. UNESCO, 2004. Disponível em: $<$ http://www.uis.unesco.org/profiles/selectCountry_en.aspx $>$. Acesso em: jan. 2009.

VON LINSINGEN, Irlan. CTS na educação tecnológica: tensões e desafios. I CONGRESO IBEROAMERICANO DE CIENCIA, TECNOLOGÍA, SOCIEDAD Y INNOVACIÓN CTS+I. México D.F. Memórias del Congreso Ibero CTS+I, 2006. v. 1. p. 1-14. 